\title{
A Economia Política do Gênero: Determinantes da Divisão do Trabalho*
}

\author{
The Political Economy of Gender: \\ Determinants of the Division of Labor
}

ANITA KON **

\begin{abstract}
RESUMO: Este artigo examina algumas discussões recentes sobre divisão de trabalho entre gêneros que ocorrem no campo da economia política. Ele analisa abordagens teóricas que enfatizam a necessidade de uma teoria menos rígida, em seus limites disciplinares, e rejeita o conceito de Economia como uma entidade a-histórica e sem corpo. Discute a distribuição ocupacional de gênero, começando com um ponto de vista histórico sobre o desenvolvimento desse fenômeno e observando os impactos da demanda e da oferta de determinantes do mercado de trabalho, os efeitos da reestruturação econômica e as causas das diferenças salariais. PALAVRAS-CHAVE: Trabalho; gênero; economia; políticas públicas; desenvolvimento; flexibilidade do trabalho.
\end{abstract}

ABSTRACT: This article examines some recent discussions about labor division between genders that take place in the field of Political economy. It analyses theoretical approaches that stress the need of a less rigid theory, in its disciplinary boundaries, and reject the concept of Economy as an ahistorical, disembodied entity. It discusses the gender occupational distribution, beginning with a historical point of view about the development of this phenomenon, and observing the impacts of the demand and offer determinants of the labor market, the effects of economic restructuring and causes of wage differences.

KEYWORDS: Work; gender; economy; public policies; development; labor flexibility. JEL Classification: J01; J7; J16.

\section{CONSIDERAÇÕES INICIAIS}

O estudo da Economia do Gênero tem apresentado maior desenvolvimento nas duas últimas décadas, tanto no que se refere ao interesse teórico pelo tema

\footnotetext{
* O presente artigo baseia-se em pesquisa financiada pelo Núcleo de Pesquisas e Publicações da EAESPFGV, a quem a autora agradece.

** Professora da Pontifícia Universidade Católica - PUC, São Paulo/SP, Brasil. E-mail: anitakon@pucsp. br. Orcid: 0000-0002-2217-4381.
} 
quanto à atividade de pesquisa empírica, tendo em vista os crescentes problemas de absorção de mão-de-obra enfrentados neste período pelo capitalismo. Os trabalhos de análise então desenvolvidos assumem de forma explícita que a existência de dois gêneros tem efeitos consideráveis nos agentes econômicos, em sua interação com as famílias, empresas e mercados.

Este artigo examina algumas discussões mais recentes sobre gênero, desenvolvidas no âmbito da Economia Política, particularmente no que se refere aos determinantes da divisão de trabalho, buscando um entendimento multidisciplinar sobre o fenômeno. $\mathrm{Na}$ atualidade, um número crescente de estudiosos vêm adotando abordagens teóricas e metodologias mais abrangentes neste campo, como os institucionalistas, os economistas sociais, os pós-keynesianos, permitindo um pensamento menos rígido em suas fronteiras disciplinares e rejeitando a idéia da economia como uma entidade a-histórica e desvinculada das transformações que possam ocorrer na base do comportamento dos agentes e fenômenos econômicos.

Neste sentido, os enfoques dessas discussões tentam conciliar várias vertentes teóricas, ou criticar suas insuficiências. Entre as diferenças, salientam que as teorias marginalistas visualizam a renda ou a capacidade de ganhar renda como restrição principal, enquanto os marxistas consideram os limites definidos pela posição do indivíduo no sistema de classes. Enfatizam que para estes, apenas os capitalistas têm a capacidade de criar renda suficiente através da propriedade do capital para favorecer seus interesses, enquanto a classe trabalhadora teria possibilidade apenas de ganhar o suficiente para o sustento, mas nunca de ultrapassar o nível de subsistência básica. Por outro lado, economistas que defendem o feminismo vêem limites à plena participação da mulher no sistema econômico, enquanto os institucionalistas consideram as restrições nas formas de instituições como governos, sindicatos, e nos sistemas legais e tradicionais; acreditam que as instituições são criadas não para favorecerem interesses dos indivíduos, mas sim para satisfazer outras metas sociais, enquanto algumas vertentes teóricas mais tradicionais consideram que as instituições favorecem a consecução dos interesses próprios, de grupos sociais particulares.

As várias escolas tradicionais de pensamento, de um modo global, não se dedicaram a uma análise mais detalhada dos diferentes papéis e impactos a que os agentes econômicos que compõem a família estão sujeitos, a partir de sua condição de gênero. Desconsideram o fato de que, desde a economia predominantemente rural ou pré-industrial, dentro da família, o homem e a mulher desempenhavam papéis relevantes distintos enquanto produtores de bens e serviços à sociedade. A nova Economia Política do Gênero, tem sido moldada com a preocupação de entender o papel de ambos os sexos para a reprodução econômica e social em uma nova fase do desenvolvimento capitalista, em que crescentes mudanças sistêmicas caracterizam o processo de incorporação dos trabalhadores nas esferas produtiva e distributiva das economias.

Tendo como enfoque a compreensão da distribuição do trabalho entre os sexos, não é objetivo específico deste ensaio revisar e discutir detalhadamente a diversidade das abordagens teóricas e o contexto histórico que as condicionam, mas apenas salientar que estas novas discussões vêm absorvendo a visão de várias fon- 
tes que refletem uma gama de interesses, princípios e metodologias, a partir de abordagens diversas, dialogando com uma teoria econômica progressiva e voltada para as políticas públicas. As atuais diretrizes no âmbito de interesses da Economia Política do Gênero, foram definidas em recente congresso ${ }^{1}$ que reuniu estudiosos da área para a discussão sobre as abordagens à questão de gênero nas análises econômicas, como uma forma de fornecer maior compreensão sobre o tema, de modo a aperfeiçoar a teoria econômica e de aproximá-la das políticas públicas.

Essas discussões expuseram os limites que as análises tradicionais apresentam quando não incorporam a questão do gênero, no que diz respeito à análise do mercado de trabalho e do comportamento da família enquanto unidade econômica. O gênero em si é apresentado na atualidade como uma construção complexa e estes estudos enfatizam a contingência histórica dos gêneros e sua reformulação durante os períodos de transformação econômica. Alguns autores propõem uma análise em que gênero é adicionalmente relacionado a classe e raça para a complementação do entendimento (Mutari, Boushey e Fraher IV, 1997).

Embora o interesse pelo estudo da questão de gênero na Economia Política tenha emergido particularmente com os movimentos feministas dos Estados Unidos nos anos 60, a visão da necessidade de compreensão do papel diferenciado entre os sexos, enquanto agentes econômicos produtores ou consumidores, se disseminou ampla e rapidamente entre uma série de analistas que propõem a ampliação da visão das políticas públicas, para contemplar de forma específica estas questões não previstas pela teoria da Economia Política tradicional.

Nesse sentido, mesmo a teoria tradicional marxista e a teoria neoclássica ainda têm sido utilizadas para a argumentação de que a emergência do capitalismo e a racionalidade das relações de mercado tendem a debilitar as bases sociais e culturais da predominância do patriarcalismo nas análises sobre a família e o mercado de trabalho. Os primeiros debates nos anos sessenta, tinham um cunho "marxistafeminista" e se centravam sobre a utilização apropriada de certas categorias-chave marxistas para analisar as experiências das mulheres na força de trabalho ou fora dela. Por exemplo, o debate sobre trabalho doméstico colocava a questão de se a teoria do valor de trabalho de Marx poderia ser aplicada ao trabalho de reprodução das forças de trabalho doméstico. O trabalho das mulheres em casa criaria valor adicionado e no caso positivo quem se apropriaria deste? De modo semelhante discutiam se o conceito de exército de reserva de Marx era no sentido de um montante de trabalhadores empregados de forma marginal que eram usados para pressionar os salários para baixo e se poderia ser aplicado a mulheres casadas (Mutari, Boushey e Fraher IV, 1997: 5).

De forma explícita ou implícita, estas discussões englobavam duas questões básicas: a) o papel do trabalho pago ou não pago da mulher para a perpetuação do capitalismo e b) a primazia relativa dos interesses de classe ou gênero na eco-

\footnotetext{
${ }^{1}$ Congresso sobre "Economia Política e Gênero" (Gender and Political Economy) organizado pela New School for Social Research, New York, Abril/1996.
} 
nomia. Quem se beneficiaria do trabalho doméstico não-remunerado: os homens enquanto esposos, ou os capitalistas que necessitavam que seus trabalhadores fossem nutridos e sustentados? Quem se beneficiaria dos baixos salários femininos e do status secundário das mulheres enquanto trabalhadoras?

Essas questões iniciais parecem consideravelmente reducionistas, uma vez que traziam como base um modelo particular de relação entre gêneros, que vem sofrendo transformações no decorrer da história do mundo, ou seja, que visualiza o homem enquanto o responsável pelo sustento da família e a mulher como trabalhadora doméstica. Nessas análises são ignoradas as variações históricas e culturais que podem ter ocorrido, assim como nas tradicionais análises de Economia Política. No entanto as influências destas primeiras considerações sobre gênero ainda se fazem sentir, desde que trouxeram para a discussão o reconhecimento sistemático da contribuição econômica do trabalho doméstico, ao criar e regenerar a força de trabalho enquanto insumo produtivo. Por outro lado, colocou em debate a questão do trabalho econômico doméstico não-remunerado, desafiando a dicotomia da teoria tradicional entre trabalho e lazer.

As mudanças sociais, econômicas e políticas que repercutiram no modelo "patriarcal” de família, se tornaram mais intensas e visíveis na década de 80 , quando se acentuaram as mudanças nos processos de produção manufatureira dos países industrializados e salientou-se a expansão dos serviços e dos setores informação, ao mesmo tempo em que se observou a integração de mercados globalizados e a transferência do modelo de welfare state keynesiano para novos caminhos da política pública e da visão de Economia Política. O processo de reestruturação econômica e as transformações nas instituições sociais e políticas que foram postas em prática desde então trouxeram consigo a necessidade da discussão mais detalhada sobre a questão de gênero nas relações econômicas, como uma dimensão relevante das mudanças históricas que merecem a atenção diferenciada das políticas públicas.

Como salienta Jacobsen (1998, pp. 18-19), as discussões atuais no âmbito da Economia Política sobre a questão de gênero, destacam duas perspectivas diferenciadas, que foram denominadas de "maximalista" e "minimalista". ${ }^{2}$ A perspectiva maximalista, também denominada de essencialismo, considera diferenças básicas entre os sexos. Alguns analistas que seguem esta visão acreditam que as diferenças sejam essencialmente biológicas; outros acreditam que são produto de condições sociais vigentes desde o início da vida, ou situadas nas diversas condições psíquicas observadas nos dois sexos, através dos processos psicanalíticos da criação de identidade; outros ainda consideram todos estes aspectos conjuntamente. De qualquer maneira, estes estudiosos consideram que essas diferenças estão profundamente enraizadas e resultam em abordagens diferenciadas do mundo, criando distintas culturas: uma "cultura masculina" e uma "cultura feminina", que têm implicações

\footnotetext{
${ }^{2}$ Os representantes principais destas correntes de pensamento para o essencialismo são Catherine Stimpson, Carol Gilligan e particularmente Shulamit Firestone, e para o construtivismo Eleonor Emmons Maccoby e Carol Nagy Jackin.
} 
políticas variadas e beneficiam de forma diversa a sociedade; a sociedade reconhece estas diferentes contribuições e recompensa de forma também diferenciada o cumprimento do papel de cada sexo.

A perspectiva minimalista, chamada de construtivismo, defende a idéia de que os dois sexos são fundamentalmente similares, e que a diferença nos gêneros ligada às funções sexuais, como por exemplo reprodução, não necessariamente são relacionadas a traços psicológicos ou papéis sociais. Essa visão critica a noção de que a cultura da mulher, bem como os valores e o comportamento psíquico, sejam diferenciados dos do homem. As diferenças de comportamento observadas então seriam atribuídas apenas a um sistema de controle social que prescreve comportamentos específicos para o homem e para a mulher.

É necessário esclarecer que nas análises econômicas sobre a questão de gênero na atualidade, as diferenças entre homens e mulheres não se restringem às questões biológicas relacionadas ao sexo do indivíduo (homem ou mulher), mas constituem em uma série de atributos psicológicos, sociais e/ou culturais (gênero feminino ou masculino). A análise ocupacional sócio-econômica, dessa forma, transcende a simples observação de dados estatísticos sobre a alocação dos trabalhadores em determinadas categorias de trabalho segundo o sexo, uma vez que, na atualidade, o gênero é considerado uma categoria analítica relacional, referindo-se à organização social das relações entre os sexos (Bruschini, 1995: 83).

Bruschini chama a atenção para o fato de que nas sociedades ocidentais, das quais a brasileira é um exemplo, essas relações ainda são predominantemente assimétricas e hierárquicas, e são desiguais as posições ocupadas pelos indivíduos dos dois sexos seja na esfera da produção ou das relações familiares. As oportunidades de trabalho oferecidas para cada sexo, decorrem em grande parte da consideração sobre o papel da mulher na sociedade no âmbito familiar e doméstico, e sua capacidade de conjugar o trabalho profissional com o doméstico, bem como da qualificação ou capacitação (que recebe uma conotação diferenciada de escolaridade) para exercer ocupações de maior responsabilidade.

\section{DESENVOLVIMENTO HISTÓRICO DA DIVISÃO DO TRABALHO ENTRE OS SEXOS}

Existem evidentes indícios históricos de que a contribuição ao valor adicionado da economia de uma sociedade, desde o século XVIII, não era apenas efetuada por trabalhadores do sexo masculino. A participação da mulher na força de trabalho, ou seja, a contribuição da mulher ao produto gerado pela economia já se fazia presente na economia rural dos séculos XVIII e XIX (Coleman, 1997: 42-44). A economia colonial daquele período era desenvolvida em uma série de comunidades que mantinham recursos de produção comuns, o que permitia às fazendas de uma determinada área geográfica o investimento em algumas ferramentas essenciais de trabalho que eram compartilhadas. Tanto produtos acabados quanto o trabalho dos indivíduos eram comercializados dentro das comunidades, e os mercados de 
escambo, paralelamente à economia de subsistência, abasteciam as necessidades da comunidade agrária.

Um modelo econômico moldado mais recentemente por Jacobsen (1998: 14) e que descreve as funções da família no sistema econômico, permite visualizar a produção doméstica proporcionando um aumento na utilidade dos membros da família, através de várias formas que permitem uma contribuição à geração de renda e riqueza da sociedade, pela economia de tempo ou dinheiro e ainda pela geração e distribuição de produto. Primeiramente, a economia de tempo é avaliada pela utilização desse tempo na produção doméstica paga e a renda ganha com essa economia pode ser utilizada para a compra de bens intermediários (como sabão, por exemplo), que são gastos no trabalho doméstico não-remunerado, que produz bens ou serviços finais (como limpeza de roupas da família), ou para a compra de produtos no mercado (vestuário). No cômputo global do valor adicionado à economia, essa economia de tempo e dinheiro doméstico tem uma contribuição significativa. Além disso, o excedente de produção vendido no mercado, além de contribuir para o consumo que satisfaz necessidades de outras famílias, acrescenta um valor utilizado não apenas nas despesas familiares, mas também contribui muitas vezes para a poupança global da sociedade.

O trabalho conjunto da unidade familiar, por outro lado, pode contribuir para a economia de tempo ou dinheiro de forma mais ampliada do que o trabalho individual, aumentando a produção per capita familiar. São definidas algumas fontes de diminuição de custos potenciais do trabalho familiar, que acrescentam valor à produção da economia como um todo: a) a compra de insumos intermediários em quantidades maiores, tendo em vista o maior poder de barganha coletiva, que resulta na realização de maior poupança por unidade; b) custos médios inferiores de capital fixo (instalações, bens domésticos duráveis), pela maior utilização do capital, ou seja, aumento de sua capacidade de utilização; c) economias de escala no processo produtivo (como cozinhar para um número maior de pessoas); $d$ ) maior geração de produto a partir da divisão de trabalho ou especialização na família; e) processos de produção complementares. Observe-se que em todas essas fontes de diminuição de custos ou geração de renda adicionais, internas à família, os papéis específicos do homem e da mulher são claramente definidos, porém se transformam com a evolução dos valores da sociedade e com o desenvolvimento da tecnologia e dos paradigmas de produção das economias, que se transformam historicamente.

No entanto, não é apenas no trabalho doméstico que os diferentes papéis econômicos, atribuídos aos sexos pela sociedade, representam contribuições semelhantes ou diferenciadas à geração de produto. Coleman (1997: 42) relata que suas pesquisas mostram que no período, anteriormente ao desenvolvimento da manufatura, o trabalho produtivo da mulher na agricultura era quase a metade do trabalho e da produção necessária das áreas rurais, embora houvesse uma nítida fronteira entre o que seria a divisão do trabalho entre os sexos. Os homens eram encarregados da agricultura e da produção de ferramentas e outros bens manufaturados. As mulheres eram encarregadas da produção de produtos acabados usados 
pela família e pela comunidade, tais como fios e tecidos, roupas, comidas em conservas, bens cozidos, cobertores e acolchoados. Dessa forma, as mulheres transformavam produtos crus em comestíveis, como manteiga e queijo, preservavam a carne através de processos de defumação e de salga, e preservavam frutas e vegetais através de conservas. Também criavam animais como aves comestíveis, porcos e vacas. Às mulheres cabia ainda o fornecimento de serviços, como o ensino, cuidados médicos e cuidado dos dependentes. A mulher não produzia simplesmente para o consumo na residência, e o excedente da produção de produtos domésticos era programado para distribuição tanto na residência quanto na comunidade. Com exceção de alguns produtos que utilizavam os trabalhos dos dois sexos, como por exemplo sapatos, os bens que as mulheres produziam eram a base dos mercados de escambo que supriam as necessidades diárias da comunidade. Os bens acabados produzidos por homens, como visto, eram mais utilizados como insumos para a construção de imóveis e para a agricultura, como ferramentas e produtos de vidro, madeira, metais.

Quando os meios de produção domésticos e da comunidade rural começaram a ser controlados por mercadores e especuladores, a produção doméstica passou por uma revolução profunda. Tanto a produção artesanal masculina quanto a doméstica feminina se tornaram trabalho assalariado, seja dentro de casa ou na fábrica, e os que produziam as mercadorias não mais controlavam a distribuição do excedente de sua produção. O trabalho doméstico feminino assalariado passou a ser considerado "trabalho para fora" e, em uma etapa posterior, o trabalho deslocou-se do interior da residência para a fábrica, para a produção mecanizada. A partir disso, os mercados de escambo foram abarrotados pela abundância de bens mais baratos produzidos por nova tecnologia. As comunidades se envolveram cada vez mais com o trabalho assalariado à medida que a moeda, ou qualquer outro meio universal de troca, se tornou necessária.

Esse período de transição na História da Economia apenas recentemente tem sido estudado com maior detalhe. As quantidades e a disponibilidade de trabalho têm mudado nas economias, de acordo com as definições que refletem os relacionamentos de poder e as necessidades econômicas dentro da comunidade. A situação do indivíduo, diante das diferentes hierarquias de poder da comunidade, determina a que tipo de trabalho a pessoas irá se engajar. Dois tipos de fatores econômicos estavam subjacentes nas mudanças da divisão social do trabalho, que ditaram a entrada da mulher na força de trabalho assalariada: um aumento da necessidade de moeda, em economias que sofriam de escassez crônica de produtos e uma dívida rural crescente associada à escassez de terras agriculturáveis à medida da expansão agrícola.

Com o desenvolvimento da industrialização na segunda metade do século XIX e as mudanças nas condições econômicas resultantes, foram criados novos papéis nas economias, tanto para homens quanto para mulheres. Os homens tinham mais oportunidades de se engajarem em uma série maior de ocupações, como a navegação, construção de estradas e canais, serviço militar. No início do período de escassez de moeda e de terras e com a partida de homens para trabalhos em outras re- 
giões, as mulheres, antes dedicadas ao casamento e ao trabalho doméstico, viramse na contingência de prover seu próprio sustento e de enfrentar um futuro não definido pelos padrões sociais anteriores, e passaram assim a se locomover para as áreas urbanas e para as fábricas, o que acabou repercutindo tanto nas taxas de casamentos, quanto de natalidade.

Algumas teorias foram desenvolvidas no decorrer da evolução da Economia Política do Gênero para explicar porque a segregação por gênero ${ }^{3}$, nas atividades de trabalho, se formou e persiste em sociedades mais desenvolvidas. Procuram explicar que em determinadas condições a segregação poderá levar a sociedade a uma maior eficiência alocativa, definida pela distribuição de homens e mulheres na força de trabalho de modo a maximizar a produção final de bens e serviços da economia e o resultado total na melhora do bem-estar da sociedade. Alguns determinantes mais relevantes podem ser resumidos: a) diferenças entre gêneros nas capacidades para o trabalho, que conduzem à exploração das vantagens comparativas através da divisão de trabalho do mercado. Se na realidade cada sexo tem realmente predisposição para executar melhor algum tipo de tarefa, então a sociedade conseguiria maior eficiência com a segregação. Deve ser ressaltado o fato de que estas capacidades se transformam com a possibilidade de qualificação da mão-de-obra; b) eficiência na separação dos gêneros de modo a reduzir os conflitos no trabalho, relacionados a tensões entre os sexos; c) necessidade de equilibrar o trabalho de mercado com o doméstico e outros afazeres familiares. Em algumas sociedades mais avançadas da atualidade, algumas atividades, anteriormente distribuídas pelo mercado, são estimuladas a serem desempenhadas no ambiente doméstico, como forma de redução de custos para a sociedade e maior eficiência (como por exemplo, cuidado dos velhos, de grupos de crianças, ou de doentes convalescentes); d) informação imperfeita acerca das capacidades relativas entre os dois gêneros, da parte dos empregadores; e) exploração de parte das mulheres por homens ou por outro subsetor da sociedade.

\section{CONDICIONANTES DA PARTICIPAÇÃO DOS GÊNEROS NO MERCADO DE TRABALHO}

De uma maneira geral, a teoria econômica tenta explicar as mudanças na oferta individual de trabalho observando as mudanças nos salários e na renda dos indivíduos. No entanto, é possível verificar muito claramente a influência de outros fatores importantes. A recente literatura econômica apresenta algumas análises que tentam explicar o aumento da participação da mulher no mercado de trabalho e a queda da representatividade masculina, particularmente pesquisando o período após a Segunda Guerra Mundial (Jacobsen, 1998; Gilman, 1998; Alves, 1999; Li-

\footnotetext{
${ }^{3}$ Destacam-se os trabalhos: Long (1958), Cain (1966), Smith and Ward (1985), Oppenheimer (1976), Vanek (1974), Michael (1985) e Grossbard-Schechtman (1994), entre outros.
} 
berato, 1999; Folbre, Bergmann, Agarwal and Floro, 1992). Resumidamente, os determinantes são caracterizados como fatores de demanda e de oferta de trabalho.

Com relação ao aumento da participação feminina, entre os fatores de demanda por trabalho, salientam-se três aspectos principais: a) o aumento geral da demanda por trabalho do período. Embora sujeita às flutuações dos ciclos econômicos, observou-se que no século XX, esta demanda foi crescente até os anos 80, uma vez que o mercado de bens e serviços (interna e internacional) aumentou, apesar da inovação tecnológica do período que contribuiu para o aumento da produtividade por trabalhador; b) aumento setorial na demanda por trabalho, resultante da evolução das economias. Este leva à necessidade de diferentes formas de trabalho, que refletem o mix de bens e serviços. Novas especializações e novos tipos de ocupações definem a elevação de uma demanda adicional em setores específicos; c) a elevação na escolaridade feminina, que transformou grande parte de trabalho não qualificado em qualificado, possibilitando maior absorção de mulheres aos processos industriais mais complexos.

Os fatores de demanda influenciam as decisões individuais das mulheres de oferecer seu potencial de trabalho no mercado, tendo em vista o aumento do valor dos salários pagos. No que se refere aos fatores atuantes via oferta de trabalho feminino, são considerados alguns determinantes que resultam em mudanças na curva de oferta: a) mudança tecnológica, que apresenta dois aspectos. Por um lado a maior disponibilidade de substitutos de produtos não-mercantilizados ou domésticos, por produtos de mercado a preços baixos, o que aumenta a curva de preferências do consumidor, induzindo à procura de maiores ganhos para consumo. Por outro lado, a mudança para maior eficiência na produção não-mercantilizada doméstica e para a disponibilidade de maior tempo a ser dedicado ao trabalho no mercado; b) mudanças na composição da família, que podem afetar a decisão de oferecer trabalho no mercado, particularmente as tendências no número de casamentos e idade de casamento, divórcios, tamanho da família; c) queda dos salários reais médios familiares, que estimula à ida da mulher ao mercado de trabalho.

Para a explicação da queda da representatividade masculina na força de trabalho, os fatores de demanda são resumidos em: a) declínio setorial da demanda por trabalho em setores em que os empregados são predominantemente do sexo masculino, particularmente no setor manufatureiro; b) a crescente substituição do trabalho masculino por feminino (quando são substituíveis), visando a diminuição de custos e de relaxamento do padrão de exigência dos trabalhadores.

Ao lado da oferta de trabalhadores, os determinantes principais dessa queda são explicados como: a) elevação dos salários reais, que tem o efeito de prolongar o tempo útil potencial da renda e de antecipar a aposentadoria; b) aumento em outras formas de renda, que não do trabalho (renda futura de programas de pensões, seguros ou outras formas de renda potencial, como poupança).

Uma série de outros fatores que são válidos para explicar algumas tendências mais recentes, como: mudanças na mentalidade das sociedades, transformações nas diferenças nas classes sociais, mudanças nas condições de trabalho e na intensidade do esforço de trabalho requerida (com a mudança tecnológica), aumentos nos 
benefícios extra-salariais (fringe benefits), mudanças no movimento sindical, aumento da dependência da vida social em relação ao trabalho, mudanças na distribuição de renda, nos encargos das dívidas, na riqueza, nos ativos líquidos e nas atividades de lazer.

\section{REESTRUTURAÇÃO ECONÔMICA E GÊNERO}

Quando se analisa especificamente as questões relacionadas ao trabalho, as hipóteses básicas que fundamentam o processo de desenvolvimento econômico dos últimos anos, são de que a aceleração do progresso tecnológico e de globalização econômica, que obrigou a uma reestruturação tecnológica e organizacional das empresas na maior parte dos países, teve repercussões consideráveis sobre a natureza dos processos produtivos, sobre a composição interna dos setores e sobre a evolução e natureza do produto. Esta dinâmica teve impactos transformadores sobre as condições e a natureza do trabalho, em todos os setores econômicos.

Transformam-se também os requisitos essenciais da força de trabalho para assumir novas técnicas em um mesmo setor de atividades ou novas ocupações em setores diferenciados. A necessidade de especialização do trabalhador em tarefas repetitivas, vem sendo substituída pela necessidade de adequação a constantes mudanças tecnológicas e à possibilidade de atender a funções diferenciadas nos processos produtivos e distributivos das economias, na atualidade caracterizados pela flexibilidade na operacionalização como forma de redução de custos. As transformações estruturais ocorrentes internamente aos setores de atividades das economias, que por um lado se revestem de um caráter novo e inovador, por outro lado desempenham um papel desequilibrador em relação à criação de um volume de postos de trabalhos necessários para o crescimento da força de trabalho.

No período de reestruturação produtiva intensificado nos anos 80 , a teoria keynesiana baseada na demanda como inspiração das políticas públicas e das sugestões dos economistas para a resolução dos problemas de desenvolvimento, cedeu paulatinamente lugar a uma retomada da valorização do papel do mercado como categoria central do discurso econômico. A palavra-chave dessa linha de análise é flexibilidade, ligada ao conceito de competitividade, em um período de elevada competição internacional e "acumulação flexível". Flexibilidade pode ser aplicada tanto a relações de trabalho quanto à especialização flexível, determinada pela diferenciação do produto.

A flexibilização do mercado de trabalho tem sido apontada como uma dimensão crucial do processo, como meio de permitir que as empresas se adaptassem às mudanças nas condições de mercado. As políticas públicas também foram redirecionadas, tanto em países desenvolvidos quanto nos menos avançados, para eliminar pontos de rigidez que poderiam bloquear as operações dos mercados de produtos e de trabalho.

Como salienta Rosenberg (1991), o caminho para a flexibilidade toma três formas básicas: a) flexibilidade salarial, que reafirma o papel central das forças de 
oferta e demanda nos mercados externos de trabalho, sinalizando para o retorno das noções clássicas de equilíbrio do livre mercado. Essa forma de flexibilização é buscada através da desregulação do mercado de trabalho, diminuindo implícita ou explicitamente os padrões do salário mínimo e permitindo a negociação entre as partes envolvidas; b) flexibilidade de emprego ou numérica, que tem a mesma conotação da anterior e diz respeito às formas de contratação diferenciadas, como em tempo parcial, temporária, subcontratação, trabalho em domicílio e outras que funcionam como meio de aumentar as taxas de emprego; c) flexibilidade funcional, que ocorre nos mercados internos de trabalho (dentro das empresas), e que reduz o poder tradicional dos trabalhadores dos setores sindicalizados, através da flexibilização das características e dos requisitos para a escolha dos candidatos aos postos de trabalhos; esse fenômeno vem acompanhado freqüentemente da redução da política de carreiras e da mobilidade interna do trabalhador em direção à ascensão dentro das empresas.

A questão de gênero acrescenta uma nova perspectiva a essa análise da flexibilidade, pois cada uma dessas formas de flexibilidade recebe forte influência do sexo do trabalhador. A flexibilidade salarial afeta o salário familiar do trabalhador masculino, pois cada vez mais os trabalhos são pagos em consonância aos salários femininos (quando possível a substituição da função por trabalhadora feminina), que são inferiores. A flexibilidade no emprego é obtida freqüentemente através do uso de trabalhadores em tempo parcial ou temporários, a que particularmente se adaptam um grande número de mulheres. A flexibilidade interna, por sua vez, transforma as condições de trabalho nas indústrias em que predomina o trabalho masculino, para substituição por um emprego semelhante e "secundário" (com poucas perspectivas de promoção e condições vagas de efetivação no posto de trabalho) exercido por uma mulher.

As diferenças no valor do salário entre gêneros, em uma grande parte de ocupações, não tem uma causa biológica relacionada às diferenças nas habilidades ou na força física entre os sexos, mas tem um caráter social ainda hoje vigente na maior parte das sociedades, relacionado à atribuição das tarefas de sustento da família atribuída ao homem e de cuidados domésticos e reprodução da força de trabalho atribuídos á mulher que, como salientado anteriormente, correspondia ao modelo do século XIX.

Grande parte desta flexibilização no mercado de trabalho foi conseguida devido à falta de eqüidade no pagamento do trabalho entre os sexos e a falta de eqüidade é defendida por muitos analistas, como uma forma de possibilitar às forças de mercado se adaptarem e responderem às condições de mudança econômica. Assim, salários mais altos são utilizados para diminuir a escassez de oferta de trabalhadores em determinada ocupação ou posto de trabalho e salários mais baixos são utilizados quando há excesso de oferta de trabalhadores; valores comparáveis ou eqüitativos não permitiriam esta flexibilidade. A defesa destes mecanismos de mercado está entre as suposições explícitas da teoria do valor da economia neo-clássica. Nesse caso, a regulação governamental dos salários, a eqüidade 
nos valores pagos para os gêneros e outras formas de regulação introduzem uma rigidez e barreiras à competitividade (Mutari e Figart, 1997: 122).

Enquanto a maior parte da expansão econômica do período de reestruturação produtiva nos anos 80, nos países mais avançados da Europa, nos EUA e no Japão, se baseou nos setores industriais em que tradicionalmente predominavam ocupações masculinas e trabalhos sindicalizados, a reestruturação econômica colocou os setores em que prevalecem o trabalho feminino, como relevantes nas economias ditas pós-industriais. Uma nova visão foi introduzida, de "feminização global através do trabalho flexível" (Standing, 1989), em que foi apresentada uma análise das tendências unificadas tanto de países mais avançados como em desenvolvimento, em que a feminização era parte de um estratégia direta do empregador, para diminuir salários e aumentar o controle sobre mercados de trabalho internos (às empresas) e externos. Essa estratégia de feminização se apoiava na situação de marginalização da mulher no mercado de trabalho, bem como nas suposições da "docilidade" e "domesticidade" da mulher, o que facilitaria as relações de trabalho.

A feminização definida por Standing resulta de mudanças estruturais na natureza do emprego, bem como nas participações dos sexos. Esse processo engloba três aspectos principais: a) substituição direta de homens por mulheres em postos de trabalho; b) a expansão de setores tradicionalmente intensivos em trabalho feminino; c) expansão de formas de emprego associados a mulheres, tais como os de tempo parcial, temporários e informais. O autor salienta que a desregulação e as estratégias flexíveis de emprego, fomentaram os tipos de trabalho, de relações de trabalho, de renda e de insegurança associados geralmente ao trabalho feminino.

Os processos recentes de feminização das ocupações industriais particularmente em países mais avançados, têm se desenvolvido paralelamente ao processo de desindustrialização, quando se observa no mundo uma tendência constante ao aumento das taxas de representatividade da mulher no mercado de trabalho. No entanto, diferentemente do que acontece em países mais avançados, nos países em desenvolvimento esse aumento se deve apenas em parte às mudanças culturais, demográficas e econômicas voltadas à modernização social e ao desenvolvimento econômico, porém observa-se também que mesmo em períodos de crises sócio-econômicas conjunturais, a participação da mulher no mercado de trabalho tem aumentado como conseqüência da necessidade de complementação (ou como única fonte) da remuneração familiar. De qualquer forma, as condições diferenciadas por gênero em relação a responsabilidades familiares e profissionais, horários de trabalhos rígidos, exigências mais estritas de qualificação em relação ao homem, entre outras, tornam patente que o trabalho da mulher não depende apenas da demanda do mercado, mas também de uma série de outros fatores a serem articulados (Bruschini, 1996). Estes fatores conduzem freqüentemente à alocação de trabalhadoras em atividades informalizadas, que permitam mais facilmente esta articulação, mas que se revestem de um caráter instável e de menor remuneração. O trabalho domiciliar é uma solução freqüentemente encontrada pela mulher na sociedade contemporânea (Abreu e Sorj, 1993; Bruschini e Ridenti, 1993). No entanto, ao contrário do trabalho domiciliar resultante da terceirização de uma 
série de serviços modernos mais sofisticados, anteriormente alocados nas empresas, o trabalho domiciliar feminino, na maior parte dos casos, tem se revestido de um caráter artesanal, baixa qualificação e baixa remuneração.

\section{DETERMINANTES DE DIFERENÇAS SALARIAIS}

Entre as causas determinantes das diferenças de remuneração entre os gêneros, destacam-se a disponibilidade de capital humano, existência de diferenciais de compensação para tipos de trabalhos e a discriminação.

As diferenças sistemáticas no tipo de capital humano que explicam muitas defasagens salariais entre os sexos (Kon, 1999), podem resultar de escolhas do indivíduo sobre o tipo de capital humano a ser adquirido. Por exemplo, durante muito tempo, historicamente, as mulheres foram mais inclinadas a investir em capital humano que traria um retorno maior fora do mercado de trabalho, em ambiente doméstico ou que acarretaria maior satisfação seja no tempo de trabalho ou de lazer, enquanto os homens tendem a investir em capital humano que traga maior retorno no mercado e maiores salários, embora menor satisfação pessoal.

As formas de capital humano ligadas diretamente à força de trabalho que se dirige ao mercado de trabalho, referem-se especificamente à educação formal, treinamento especializado fora ou dentro das empresas (in the job) e experiência. Esses tipos de capital humano podem caracterizar categorias gerais ou específicas de capital. Por exemplo, a capacidade de ler seria considerada uma categoria geral, enquanto o conhecimento de música destinado a retornos monetários seria um capital específico para um determinado setor, e adicionalmente o capital pode ser ainda mais específico e relacionado, dentro de um setor, ao conhecimento da operacionalização do processo produtivo de uma determinada empresa. Dessa forma cada gênero apresenta uma combinação e estoques diferenciados de capital humano geral e específico, que acarretam diferentes taxas de retorno quando comparados no mercado de trabalho. Os diferentes estoques de capital humano relacionados à educação formal, por exemplo, referem-se aos graus de escolaridade adquiridos, desde a educação primária ou básica, passando pela secundária, universitária e prosseguindo pelos vários níveis de especialização adicionais.

Algumas teorias não consideram que o capital humano seja sempre diretamente responsável pelos diferentes retornos de um indivíduo, primeiramente porque nem sempre existe uma relação direta entre educação e remunerações, ou seja, em muitos casos a educação em si nada acrescenta à produtividade do trabalhador em determinado processo produtivo. Além disso, os teóricos institucionalistas argumentam que a relação entre escolaridade, treinamento, experiência, de um lado, e as remunerações, de outro, passa por uma série de dispositivos legais, contratuais ou acordos tradicionais, que não são necessariamente atrelados à produtividade. $\mathrm{Na}$ realidade, nem sempre o indivíduo é livre para escolher o tipo de investimento em seu capital humano que deseja efetuar, mas existem muitas barreiras à entrada para tipos específicos de investimento, ou seja, diferentes possibilidades de acesso 
e, no caso do gênero, constata-se uma discriminação em determinadas áreas que reduz a possibilidade de acesso e de remuneração do sexo feminino; isso se verifica, uma vez que determinadas atribuições sociais têm tradicionalmente implicado, mais para a mulher do que para o homem, intermitências e dificuldade de dedicação integral de tempo para aquele investimento. Além disso, as diferenças no planejamento sobre o tempo de vida útil no trabalho do homem e da mulher, levam à consideração, pelos empregadores, de que os maiores retornos ao treinamento oferecido ao trabalhador serão conseguidos com uma vida útil maior na empresa; nesse sentido, as mulheres têm sido desprivilegiadas porque alguns treinamentos devem ser efetuados em um prazo maior e por esse motivo acarretam em maiores remunerações posteriores, e as evidências têm mostrado que os homens têm apresentado uma maior vida útil nas empresas. Mas mesmo no caso de treinamentos que ocupam menor tempo, a previsão de menor vida útil do trabalho feminino afeta os ganhos dos gêneros. No caso da intermitência da mão-de-obra, a reentrada em uma ocupação pode ser considerada como um nova entrada inicial, que requer novos custos de treinamento e portanto é considerada como uma maior taxa de depreciação do capital investido.

Várias pesquisas mostram, através de evidências empíricas, grandes diferenças entre sexos no que se refere à experiência no trabalho, aquisição de treinamento no posto de trabalho e quantidade de capital humano específico, sendo os dados desfavoráveis à mulher e às suas condições de remuneração (Jacobsen, 1998: 271; Kon, 1999; Alves, 1999.). Mostram também que essas diferenças são responsáveis por cerca de $50 \%$ das diferenças nas remunerações, porém muitas das diferenças permanecem sem explicação. Alguns fatores não-mensuráveis são citados como influenciando provavelmente essas diferenças, através dos efeitos na produtividade ou nos ganhos, como: a) habilidade ou talento de cada pessoa para exercer determinada tarefa ou ocupação; b) motivação para o compromisso de trabalho; e c) características físicas (altura, peso, força física, timbre de voz, entre outras).

Outra causa de diferenças nas remunerações entre sexos é atribuída aos diferenciais de compensação, conceito já encontrado nos escritos de Adam Smith. Refere-se à constatação de que trabalhos desagradáveis ou "maus" postos de trabalho serão melhor remunerados do que os trabalhos agradáveis ou "bons" postos de trabalhos, sem se considerarem outros fatores. O adicional positivo de salário cobriria maior risco para a saúde, ameaça de desemprego, menores ganhos extrasalariais (fringe benefits) e outras condições desfavoráveis de trabalho. Os trabalhos "bons" incluiriam condições agradáveis de trabalho no ambiente, alto nível de ganhos extra-salariais (fringe benefits), alimentos e transportes subsidiados, cooperativas de consumo, baixo controle de horário; todos estes fatores levariam a um diferencial de compensação negativo. Por sua vez, os trabalhos "maus", incluem risco à saúde (como coleta de lixo), sazonalidade de emprego e outros fatores que levariam a um diferencial de compensação positivo. Dessa forma, homens e mulheres expressariam diferentes preferências por certas condições de trabalho e classificariam as oportunidades de emprego a partir destas condições.

Os efeitos da discriminação de gênero também são considerados nas recentes 
discussões econômicas como influentes nas diferenças de remunerações. Do ponto de vista econômico essa discriminação é caracterizada quando duas pessoas que possuem igual produtividade e gostos para o trabalho naquelas condições, mas são membros de diferentes grupos (definidos de acordo com alguma característica, seja de gênero, raça, classe, preferência sexual, crença religiosa, etc.), recebem diferentes resultados no local de trabalho, em termos de salários pagos e/ou acesso ao posto de trabalho.

A discussão dentro do campo econômico tende a se limitar à discriminação na forma de remuneração, nas condições de contratação e nas práticas de promoção. Por outro lado, a comprovação dessas evidências se torna difícil, tomando a forma de depoimentos diretos, pesquisas de auditoria e evidências indiretas através de informações estatísticas, que no entanto muitas vezes perdem o poder de explicação, devido à interferência de outros fatores que influenciam as variáveis, embora se encontrem na literatura alguns modelos neoclássicos que tentam explicar, através da maximização da utilidade ou dos lucros, os mecanismos de equilíbrio que consideram a discriminação (Jacobsen, 1998: 304).

Essas teorias basearam-se seja no preconceito, seja em divergências do modelo de competição perfeita. As fontes de preconceito nesses modelos podem ser tanto os empregadores, quanto os trabalhadores ou os consumidores. As divergências da competição perfeita apontam para poder de mercado, da parte de grupos da sociedade, ou para informação imperfeita sobre a produtividade do trabalhador, como visto. Estas teorias podem ser agrupadas como modelos de monopsônio, modelos de busca de diferencial de retornos, modelos de dois setores, e outros modelos estatísticos de discriminação. No entanto, cada modelo explica uma parte das implicações da discriminação e não existe um modelo abrangente que abarque vários fatores determinantes. Por outro lado, estes modelos tentam justificar a discriminação para a consecução do equilíbrio a longo-prazo.

\section{O PAPEL DAS POLÍTICAS PÚBLICAS NA DIVISÃO DO TRABALHO ENTRE GÊNEROS}

As recentes teorias, baseadas em evidências empíricas, revelam a tendência de que a segregação ocupacional vem favorecendo o sexo masculino. As ocupações desempenhadas principalmente por mulheres têm recebido ganhos inferiores do que as desempenhadas por homens, e apresentam maior rotatividade e piores condições de proteção trabalhista. Jacobsen (1998) discute se a segregação é basicamente um estado imutável ou se é possível mudanças nessa condição. Se existirem forças significativas que impelem a sociedade à segregação, existe grande probabilidade que as políticas designadas a diminuí-la sejam adaptadas a condições específicas de cada sociedade, de modo que a segregação talvez ressurja em formas menos notáveis.

A observação de algumas sociedades mais tradicionais mostra que a intervenção via políticas públicas, colocada em prática em outras áreas, ocasionou mudan- 
ças consideráveis, enquanto, com relação às diferenças entre os sexos, no que se refere a salários e absorção de trabalho, os resultados têm sido mais resistentes à mudança. No entanto, na atualidade, confirmou-se em países mais avançados, que os padrões de segregação podem ser influenciados por uma série de políticas públicas voltadas para o mercado de trabalho e destinadas a melhorar as condições de absorção da mulher, como programas de treinamento ou políticas antidiscriminatórias (Machado, 1999). Como pode ser observado, diferentes perspectivas ainda permeiam o debate encontrado na literatura a respeito do papel das políticas públicas relacionadas à desigualdade de gênero no mercado de trabalho.

De acordo com seu objetivo primordial, essas políticas podem ser definidas como: a) voltadas para influenciar os salários; as mais comumente adotadas visam elevar os salários em setores em que predomina a mão-de-obra feminina, para se compararem aos setores em que a masculina é predominante, comparando o valor de trabalhos que são comparáveis; b) as que tentam modificar o comportamento do empregador em relação à contratação e promoção; $c$ ) as voltadas mais a trabalhadores do que a empregadores e que visam o treinamento e outros programas educacionais; d) programas, como subsídios para o cuidado das crianças, que afetam a decisão familiar de entrada ou não da mulher na força de trabalho; e) as que visam especificamente a integração entre os gêneros como o resultado desejado.

As políticas que influenciam os salários são principalmente adotadas em países mais desenvolvidos, em funções governamentais locais ou estaduais, porém não se verificou efetivamente a diminuição da segregação em todos os setores. Os defensores destas políticas argumentam que salários mais elevados em ocupações onde predominam mulheres levam os homens a se dirigir a esses postos e portanto reduzem a concentração ou segregação nesses setores. Os oponentes consideram que a segregação aumentaria, pois salários mais elevados desencorajariam as mulheres a deixarem esses postos (Aaron e Lougy, 1986). Estas duas óticas são justificáveis, considerando o lado da oferta de trabalhadores, porém não consideram mudanças na demanda por trabalho. A elevação (diminuição) de salários em um determinado posto de trabalho torna o trabalho mais (menos) procurado tanto por homens quanto por mulheres, no entanto o efeito líquido sobre a segregação não é possível de previsão sem a consideração de outras forças que determinam a oferta de trabalho.

Outras políticas destinadas a influenciar o padrão de contratação e promoção dos empregadores, podem atuar através de restrições legais, que determinam uma taxa obrigatória mínima de contratação de determinado gênero (geralmente feminino), que atuam assim como as metas voltadas para discriminação de raça ou outras minorias. Em alguns setores, poderia verificar-se a ocorrência de vagas em postos específicos, quando não fosse possível competir por um número insatisfatório de pessoas qualificadas ou que se oferecem para exercê-los. Os resultados, portanto, dependem da oferta relativa de trabalhadores de cada gênero para aqueles postos.

As políticas de treinamento e educacionais visam proporcionar à força de trabalho alvo (na maior parte das vezes do sexo feminino) as condições de assumir os tipos de colocações oferecidas, o que não significa necessariamente a garantia de obtenção de trabalho, tendo em vista outros requisitos demandados pelos em- 
pregadores para contratação e promoção. Um caminho adicional de política seria a concessão de subsídios ou isenções a empregadores que apresentem esforços comprovados para a integração da mulher e equalização de salários.

Algumas políticas que influenciam a decisão feminina sobre a intensidade de participação na força de trabalho e que portanto afetam a segregação, referem-se à disponibilidade de condições de cuidados às crianças, seja através de creches no local de trabalho ou de disponibilidade destes serviços baratos e de boa qualidade fora da empresa; as licenças-maternidade e a flexibilidade na jornada de trabalho também são políticas influentes, embora as mudanças no grau de segregação têm se mostrado não significativas, com essas medidas, uma vez que a tendência das mulheres é se dirigirem principalmente aos postos de trabalho predominantemente femininos, o que aumentaria a segregação.

De um modo geral, a Economia Política do Gênero analisa os condicionantes da divisão do trabalho segundo o sexo, que refletem os movimentos líquidos das tendências conjunturais e de longo prazo das economias, em busca dos ajustamentos às transformações tecnológicas e da estrutura produtiva. Estas se apresentam de forma diferenciada, não apenas em períodos diversos da História econômica dos países, como também regionalmente entre países e internamente aos mesmos. Estas diversidades se manifestam de acordo com os impactos espaciais de políticas econômicas, associados a fatores culturais específicos, que se traduzem em padrões particulares de segmentação de cada sociedade.

\section{REFERÊNCIAS BIBLIOGRÁFICAS}

AARON, Henry J. e LOUGY, Cameron M., The Comparable Worth Controversy, Washington D.C.: Brookings, 1986.

ABREU, Alice, R. de PAIVA e SORJ, Bila, "Trabalho a Domicílio nas Sociedades Contemporâneas: Uma Revisão da Literatura Recente”, em Abreu, A.R.P. (org). O Trabalho Invisivel, Rio de Janeiro: Rio Fundo Editora, 1993.

ALVES, Arlete M. S., “World Opportunities for Women: NGO's Support to Microenterprises”, em Anais do VI Encontro Nacional de Estudos do Trabalho, Belo Horizonte, ABET, 1999.

BRUSCHINI, Cristina, "Desigualdades de Gênero no Mercado de Trabalho Brasileiro: o Trabalho da Mulher nos Anos Oitenta”, em Fernandes, Reynaldo (org.). O Trabalho no Brasil no Limiar do Século XXI, São Paulo: Editora LTr, 1995.

BRUSCHINI, Cristina e RIDENTI, Sandra, "Desvendando o Oculto: Família e Trabalho Domiciliar em São Paulo”, em Abreu, Alice Rangel de Paiva (org.). O trabalho invisível, Rio de Janeiro: Rio Fundo Editora, 1993.

COLEMAN, Margaret S., "Women's Labor Force Participation in Historical Perspective”, Mutari, E. Boushey H., Fraher, W. (org.). Gender and Political Economy, Armonk, New York: M.E.Sharpe, 1997.

CAIN, Glen G., Married Women in the Labor Force: An Economic Analysis, Chicago: University of Chicago, 1966.

FOLBRE, Nancy, BERGMANN, Barbara, AGARWAL, Bina e FLORO, Maria (eds.), Women's Work in the World Economy, Vol4, New York: New York University, 1992.

GILMAN, Charlotte Perkins, Women and Economics, New York: Dover Pub. Inc., 1998.

GROSSBARD-SCHECHTMAN, Shoshana e GRANGER, Clive W.J., "The Baby-Boom and Time Tren- 
ds in Women's Labor Force Participation”, Center for Public Economics, San Diego State University, working paper, March/1994.

JACOBSEN, Joyce P., The Economics of Gender, Mass.: Blackwell, 1998.

KON, Anita, "Reestruturação Produtiva e Terciarização", Relatório de Pesquisas 29, NPP-EAESP/FGV, Dezembro/1997.

KON, Anita, "Transformações recentes na estrutura ocupacional brasileira: impactos sobre o gênero", Relatório de Pesquisas, NPP-EAESP/FGV, 1999.

LIBERATO, Vânia Cristina, "A dinâmica do serviço doméstico remunerado nos anos noventa no Brasil”, em Anais do VI Encontro Nacional de Estudos do Trabalho, ABET, Belo Horizonte, 1999.

LONG, Clarence, The Labor Force Under Changing Income and Employment, Princeton: Princeton University, 1958.

MICHAEL, Robert T., "Consequences of the Rise in Female Labor Force Participation Rates: Questions and Probes", Journal of Labor Economics, 3(1), supplement, January/1985.

MACHADO, Leda Maria Vieira, A incorporação do gênero nas políticas públicas, São Paulo: Annablume Ed., 1999.

MUTARI, Ellen, BOUSHEY, Heather e FRAHER IV, William, Gender and Political Economy, Armonk, NY: M.E. Sharp, 1997.

MUTARI, Ellen e FIGART, Deborah M., “Comparable Worth in a Restructuring Economy”, Mutari et alii (org.). Gender and Political Economy, opus cit., 1997.

OPPENHEIMER, Valerie Kincade, The female Labor Force in the United States: Demographic and Economic Factors Governing its Growth and Changing Composition, Greenwood, Westport, 1985. ROSENBERG, Sam, "From Segmentation to Flexibility: A Selective Survey", Review of Radical Political Economics, 23, 1991.

SMITH, James P. e WARD, Michael, "Time-Series Growth in the Female Labor Force”, Journal of Labor Economics, 3(1), supplement, January/1985.

STANDING, Guy, "Global Feminization Through Flexible Work", World Development, 17 (July), 1989.

VANEK, Joann, "Household Technology and Social Status: Rising Living Standards and Status and Residence Differences in Housework", Technology and Culture, 19(3), July1978. 